Çukurova Üniversitesi Mühendislik Mimarlık Fakültesi Dergisi, 31(2), ss. 279-291, Aralık 2016

\title{
Yüksek Hızlı Tren Hatlarında Hat Kalitesine Etki Eden Parametreler Üzerine Bir Çalıșma
}

\author{
Murat Vergi TACIROĞLU* ${ }^{* 1}$, Mustafa KARAŞAHİN ${ }^{2}$, Mesut TIĞDEMİR ${ }^{3}$ \\ ${ }^{1}$ Mersin Üniversitesi, Teknik Bilimler MYO. Ulaştırma ve Trafik Hiz. Bölümü, Mersin \\ ${ }^{2}$ İstanbul Üniversitesi, Mühendislik Fakültesi, İnşaat Mühendisliği Bölümü, İstanbul \\ ${ }^{3}$ Süleyman Demirel Üniversitesi, Mühendislik Fakültesi, İnşaat Mühendisliği Bölümü, Isparta
}

Geliş tarihi: 07.06.2016 Kabul tarihi: 23.11.2016

\section{$\ddot{\mathbf{O} z}$}

Demiryolu hat bakım ve yenileme çalışmaları hat kalitesinde görülen değişimlere bağlı olarak yapılmaktadır. Hat kalitesi, hattın içinde bulunduğu işletme durumunu belirtir ve genellikle bir indeks yardımıyla sayısal olarak ifade edilir. Hat geometrisi indeksi olarak bilinen bu gösterge değerler, hat geometrisi kontrol ölçümlerinden elde edilen veriler temel alınarak hesaplanır. Bu çalışmada AnkaraEskişehir Yüksek Hızlı Tren (YHT) hattından elde edilen verilerden yararlanılarak YHT hattında hat kalitesine etki eden etkenler belirlenmeye çalışılmıştır. Bunun için ilk olarak incelenen hat güzergâh geometrisi dikkate alınarak inceleme kesimlerine ayrılmıştır. Daha sonra hat kontrol trenleri ile yapılan ölçümlerin verileri analiz edilerek hangi kesimde ne kadar bozulma oluştuğu belirlenmiş ve bozulma oluşan kesimlerde hat kalitesinin değişimi incelenmiştir. Çalışmanın sonunda ise hat kalitesine etki eden parametreleri belirlemek için çok değişkenli regresyon modelleri oluşturulmuştur. Bu modellere göre, hat kalitesine etki eden faktörler trafiğe bağlı parametreler, hat kesimi tipi ve hat kalitesinin bir önceki ölçümdeki değeri olarak belirlenmiştir.

Anahtar kelimeler: Yüksek hızlı tren hattı, Hat kalitesi, Çok değişkenli regresyon analizi, Hat geometrisi

\section{A Study on Parameters Affecting the Track Quality of High Speed Rail Tracks}

\begin{abstract}
Railway track maintenance and renewal activities are performed depending on the changes in track quality. Track quality indicates the operating condition of the track and the quality is usually expressed with a numerical index. Known as track geometry indexes, these indicator values are calculated based on data obtained from the track geometry control measurements. In this study, using the data obtained from the Ankara-Eskisehir High-Speed Rail (HSR) track, the factors affecting the track quality of HSR track were determined. For this purpose, firstly the track under investigation was divided into analysis segments considering the rail alignment geometry. Then, by analyzing the data of the track record car measurements, the degree of deterioration occured in the analysis segments and the change of track
\end{abstract}

\footnotetext{
*Sorumlu yazar (Corresponding author): Murat Vergi TACIROĞLU, mtaciroglu@mersin.edu.tr
} 
quality were examined in the segments where deteriorations occured. At the end of the study, multivariate regression models were constructed in order to determine the factors affecting the track quality. According to these models, it was determined that the factors affecting the track quality are traffic-related parameters, type of analysis segment and previous value of track quality.

Keywords: High speed rail, Track quality, Multivariate regression analysis, Track geometry

\section{GíRiș}

Demiryolunun bakımı ve onarımı için yapılması gereken işlemlerin mali giderlerinin yüksek olması, bu çalışmaların planlı ve etkin bir şekilde yapılmasını gerekli kılmaktır. $\mathrm{Bu}$ faaliyetlerin etkinliği de yapılan çalışmaların zamanlaması ile doğrudan alakalıdır. Zamanından önce yapılan bakım ve onarım çalışmaları bütçenin boşa harcanmasına neden olurken, zamanında yapılmayan çalışmalar ise var olan kusurların üstel formlarda büyümesine yol açarak, bu kusurların giderilmesi için büyük miktarlarda maddi harcamalar gerektiren onarım çalışmaları yapılmasına neden olurlar. Bakım ve onarım çalışmalarının zamanlaması hattın içinde bulunduğu durum ile alakalıdır. Hattın durumu ise demiryolu hattını oluşturan bileşenlerin yapısal kalitesi ve hat geometrisinin izin verilen sinır değerler içinde olup olmaması ile ifade edilmektedir. Demiryolu hattının durumunun belirlenmesi hat bakım ve onarım çalışmalarının önemli bir bölümünü oluşturmaktadır ve genellikle iki kısma ayrılmaktadır. Bunlardan ilki hat bileşenlerinin yapısal kalitesini belirlemek için yapılan görsel kontroller, diğeri ise genellikle kayıt cihazları ile donatılmış demiryolu araçlarından oluşan otomatik hat kontrol araçları ile yapılan demiryolu hat geometrisi ölçümleridir. Hat geometrisinin ölçümü ile hat geometrisinin kalitesini gösteren hat geometrisi indeksi değerleri elde edilmektedir.

Rayların uzaysal düzlemlerdeki konumunu ifade eden demiryolu hat geometrisi, demiryolu araçlarının raydan çıkma riski ile sürüş ve yolcu konforu üzerinde etkilidir. Bundan dolayı hat geometrisi belirli sınır değerler içinde kalmalıdır. Hat geometrisi, birden fazla parametreden oluşur. $\mathrm{Bu}$ parametreler yatay düzlemde fleş ve ekartman, düşey düzlemde ise nivelman, burulma ve dever parametreleri olarak siralanmaktadır.
Ekartman parametresi, hattın herhangi bir yerinden ray yüzeyinden $16 \mathrm{~mm}$ aşağısında ölçülen, rayların birbirlerine bakan iç yüzleri arasındaki mesafe olarak tanımlanmaktadır. Standart genişlikli hatlar için ekartman değeri $1435 \mathrm{~mm}$ olarak kabul edilmektedir. Fleş parametresi, her bir rayın hattın ortasında geçtiği kabul edilen hat eksenine göre yatay konumunu ifade etmektedir. Nivelman parametresi, rayların üst yüzeyinin düşey eksendeki konumunu göstermektedir. Dever parametresi, yatay kurplarda merkez kaç kuvvetinin demiryolu araçları üzerindeki zararlı etkilerini azaltmak amacıyla dış ray dizisi ile iç ray dizisi arasında oluşturulan yükseklik farkı olarak tanımlanmaktadır. Burulma ise belirli aralıklarla ölçülen iki dever miktarı arasındaki cebrik fark olarak ifade edilmektedir (Şekil 1).

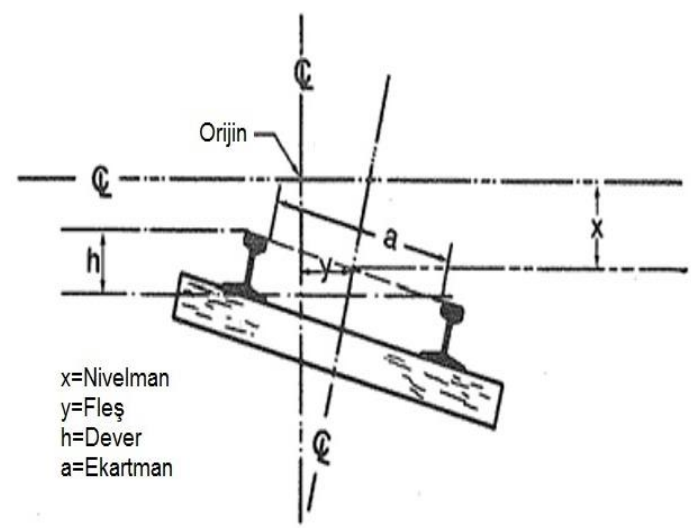

Şekil 1. Hat geometrisi parametreleri [1-2]

Hat geometrisi indeksleri, demiryolu hattının geometrisinin durumunu sayısal olarak ifade eden, hattın bakım ve onarım planlamasının yapımında kullanılan kalite göstergeleridir. $\mathrm{Bu}$ gösterge değerler hat kayıt araçlarının yaptığı ölçümlerden elde edilen hat geometrisi verilerinin çeşitli yöntemlerle analiziyle elde edilmektedir. Hattın o anki durumu hakkında fikir veren kalite 
indekslerinin geliștirilmesinde değişik ülkelerdeki demiryolu organizasyonları farklı yaklaşımlar geliştirmişlerdir.

Avrupa Demiryolu Araştırma Merkezinin (ORE) Fransa da geliştirdiği metot nivelman, fleş, dever ve hat açıklığı parametrelerinin standart sapmalarının hesaplanmasına dayanmaktadır. $\mathrm{Bu}$ yöntemde hesaplamalar için hat kayıt araçları tarafindan yapılan ölçümler $1000 \mathrm{~m}$ uzunluğundaki hat kesimleri üzerinde $18,9 \mathrm{~m}$ uzunluğunda ortakiriş dengelemesi yapılarak elde edilmektedir. Bu yöntemde yol şartlarının standart sapma değerine göre değişimi Çizelge 1'de gösterildiği gibidir [3].

Çizelge 1. Yol şartlarına göre SD değerinin değișimi [4]

\begin{tabular}{|c|c|}
\hline Yol Koşulları & $\begin{array}{c}\text { Standart Sapma Değeri } \\
\text { (SD) }\end{array}$ \\
\hline Çok iyi & $\mathrm{SD}<1$ \\
\hline İyi & $1<\mathrm{SD}<2$ \\
\hline Ortalama & $2<\mathrm{SD}<4$ \\
\hline Kötü & $4<\mathrm{SD}$ \\
\hline
\end{tabular}

Avusturya demiryolları yol geometrisi kayıt araçlarından elde edilen veriler için 5 parametreli yol kusuru değeri (W5) hesabını kullanmaktadır. $\mathrm{Bu}$ metot da temel ölçüm kesimi boyunca her bir geometri parametresi için kusur hesabı yapılmaktadır. Herhangi bir ölçüm kesimindeki, herhangi bir geometri parametresi için kusur değerinin hesab1, ölçüm kesimi içinde kabul edilebilir sınır değerlerin aşıldığ 1 yerlerin toplam uzunluğunun ölçüm kesiminin uzunluğuna bölünmesiyle yapılır (Şekil 2).

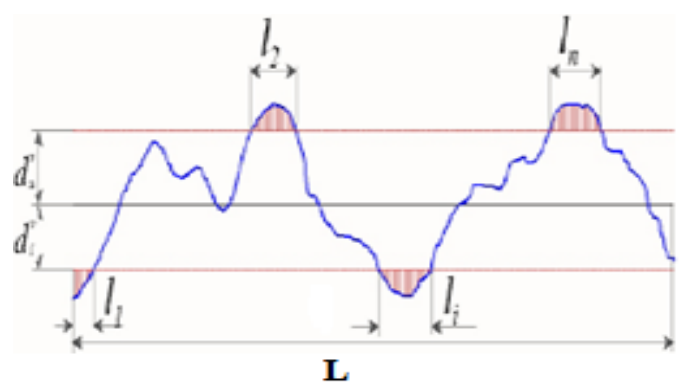

Şekil 2. W5 hesabında kullanılan uzunluklar [5]
$\mathrm{Bu}$ modele göre ölçülen her bir geometri parametresi için kusur $\left(\mathrm{w}_{\mathrm{i}}\right)$ aşağıdaki eşitlikle hesaplanmaktadır [5]:

$\mathrm{wi}=\frac{\sum \mathrm{l}_{\mathrm{i}}}{\mathrm{L}}$

Burada, $\mathrm{l}_{\mathrm{i}}$, kabul edilebilir sapma miktarının aşıldığ1 alt kesim uzunluğu, L toplam ölçüm kesimi uzunluğudur. Her geometrik parametrenin birbiri üzerindeki etkisini önemsiz kabul ederek, her parametre birbirinden bağımsız olarak değerlendirilmiştir. Böylece olasılık teorisinden yararlanarak 5 parametreli kusur değeri eşitlik 2'deki gibi elde edilmiştir:

$\mathrm{w}_{5}=1-\left(1-\mathrm{w}_{\mathrm{e}}\right)\left(1-\mathrm{w}_{\mathrm{g}}\right)\left(1-\mathrm{w}_{\mathrm{w}}\right)\left(1-\mathrm{w}_{\mathrm{y}}\right)\left(1-\mathrm{w}_{\mathrm{z}}\right)$

Burada, $w_{z}$ ve $w_{y}$ sağ ve sol rayın kusurlarından hesaplanan, sirasıyla düşey ve yatay düzensizliklerin aritmetik ortalamasıdır, $\mathrm{w}_{\mathrm{g}}$ dever kusuru, $\mathrm{w}_{\mathrm{w}}$, burulma kusuru, $\mathrm{w}_{\mathrm{e}}$, hat açıklığ 1 kusurudur. Sapmaların miktarı 18,9 m uzunluğundaki kiriş üzerinden hesap edilmektedir. Avusturya Demiryolları bu metodu kullanarak aşağıdaki Çizelge 2'yi geliştirmiştir.

Çizelge 2. $\mathrm{w}_{5}$ değerine göre yol koşullarının değişimi [5]

\begin{tabular}{|c|c|}
\hline Yol Koşulları & $\mathbf{w}_{\mathbf{5}}$ değeri \\
\hline Yeni Hat & $\mathrm{w}_{5}<0,1$ \\
\hline İyi Durumdaki Hat & $0,1<\mathrm{w}_{5}<0,2$ \\
\hline Yeterli Durumdaki Hat & $0,2<\mathrm{w}_{5}<0,6$ \\
\hline Kötü Durumdaki Hat & $\mathrm{w}_{5}>0,6$ \\
\hline
\end{tabular}

Polonyalı araştırmacılar tarafından geliştirilen $\mathrm{J}$ indeksi yol şartlarını belirlemek için kullanılmıştır. $\mathrm{Bu}$ indeks aşağıdaki formülle hesap edilmektedir [4-5].

$J=\frac{\mathrm{S}_{\mathrm{Z}}+\mathrm{S}_{\mathrm{Y}}+\mathrm{S}_{\mathrm{W}}+0,55 \mathrm{~S}_{\mathrm{e}}}{3,5}$

Burada, $S_{e}$, nivelman değerinin standart sapmas1, $S_{Y}$, fleş değerinin standart sapması, $S_{W}$, burulma değerinin standart sapması, $\mathrm{S}_{\mathrm{Z}}$, hat açıklığı değerinin standart sapması olarak isimlendirilmiştir. $\mathrm{Bu}$ yöntemde standart sapma 
ölçümleri için $10 \quad \mathrm{~m}$ uzunluğunda kiriş kullanılmaktadır. Çizelge $3 \mathrm{~J}$ indeksinin farklı hızlarda izin verilen değerlerini göstermektedir.

Çizelge 3. Farklı hızlar için $\mathrm{J}$ indeksinin izin verilen değerleri [4]

\begin{tabular}{|c|c|c|c|c|c|c|}
\hline $\begin{array}{c}\mathbf{H ı z} \\
\mathbf{( k m} / \mathbf{s})\end{array}$ & $\mathbf{3 0}$ & $\mathbf{4 0}$ & $\mathbf{9 0}$ & $\mathbf{1 2 0}$ & $\mathbf{1 6 0}$ & $\mathbf{2 0 0}$ \\
\hline $\begin{array}{c}\mathbf{J} \\
\text { Indeksi }\end{array}$ & 12,0 & 11,0 & 6,2 & 4,0 & 2,0 & 1,4 \\
\hline
\end{tabular}

İsveç Ulusal Demiryolları yol geometrik koşullarını değerlendirmek için Q indeksi değerini kullanmaktadır. $\mathrm{Bu}$ indeks istatistiksel analizlere dayanmaktadır ve aşağıdaki şekilde hesap edilmektedir [6].

$\mathrm{Q}=150-100\left[\frac{\sigma_{\mathrm{H}}}{\sigma_{\mathrm{H}_{\mathrm{lim}}}}+2 \times \frac{\sigma_{\mathrm{S}}}{\sigma_{\mathrm{S}}}\right] / 3$

Burada, $\sigma_{\mathrm{H}}$, sağ ve sol nivelman değerlerinin standart sapmalarının ortalaması, $\sigma_{\mathrm{S}}$, fleş, dever ve hat genişliği değerlerinin standart sapmalarının ortalamas1, $\sigma_{\mathrm{Hlim}}$, yol kategorisine göre $\sigma_{\mathrm{H}}$ 'nin izin verilen limit değeri, $\sigma_{\text {Slim }}$ ise yol kategorisine göre $\sigma_{\mathrm{S}}$ 'nin izin verilen limit değeridir. İsveç Demiryolları sapma ölçümlerinde $12 \mathrm{~m}$ uzunluğunda kiriş kullanmaktadır. Q indeksinin minimum değeri 50 ve maksimum değeri ise 150 dir. İzin verilen limit değerler ise 70 ve 90 arasındadır.

Hindistan demiryolları standart sapmaları dikkate alan TGI (Hat Geometri İndeksi) değerini geliştirmiştir. TGI değerinin hesabı için farklı geometrik parametreler dikkate alınır. Bu indeks, yol bozulmasının göstergesi olan dört geometrik parametrenin fleş, burulma, nivelman, hat açıklığ fonksiyonu olarak hesaplanır. Bu değer, geometrik parametrelerin önem derecelerine göre yol kalitesine olan etkileri dikkate alınarak elde edilmiştir [7].

$\mathrm{TGI}=\frac{2 \mathrm{UI}+\mathrm{TI}+\mathrm{GI}+6 \mathrm{AI}}{10}$

Burada, TGI, yol geometri indeksi, UI, nivelman, GI, hat açıklığı, TI, burulma, AI ise fleş indeksi değerleridir.
Geometrik parametre değerleri, yol geometrisi ölçüm araçlarının her bir parametre için yol yüzeyinde yaptığı ölçüm sonuçlarının standart sapmalarının aşağıdaki formülde hesaba katılmasıyla elde edilir.

GI,UI,TI,AI $=100 \mathrm{e}^{\frac{\mathrm{SDm}-\mathrm{SDn}}{\mathrm{SDu}-\mathrm{SDn}}}$

Burada, SDm, ölçülen parametre değerinin standart sapması, SDn, Ölçülen parametrenin yeni döşenmiş hat için standart sapma değeri, SDu, ölçülen parametre için gereken acil bakım değerinin standart sapmasıdır. Geometri paramtereleri için standart sapma değerleri Çizelge 4'de gösterilmektedir. Çizelge 5'de ise TGI değerlerinin yol koşullarına göre değişimi gösterilmektedir.

Çizelge 4. Geometrik parametreler için standart sapma değerleri [7]

\begin{tabular}{|l|c|c|c|c|}
\hline \multirow{2}{*}{ Parametre } & \multirow{2}{*}{$\begin{array}{c}\text { Kiriş } \\
\text { uzunluğu } \\
(\mathbf{m})\end{array}$} & \multirow{2}{*}{$\begin{array}{c}\text { SDn } \\
(\mathbf{m m})\end{array}$} & & \multicolumn{2}{|c|}{ Sdu (mm) } \\
\cline { 4 - 5 } & & & $\mathbf{V}>\mathbf{1 0 5}$ & $\mathbf{V}<\mathbf{1 0 5}$ \\
$\mathbf{k m} / \mathbf{s t}$ & $\mathbf{k m / s t}$ \\
\hline Nivelman & 9,6 & 2,5 & 6,2 & 7,2 \\
\hline Burulma & 3,6 & 1,75 & 3,8 & 4,2 \\
\hline Hat açıklığı & - & 1 & 3,6 & 3,6 \\
\hline Fleş & 7,2 & 1,5 & 3 & 3 \\
\hline
\end{tabular}

Çizelge 5. TGI değerine göre yol koşullarının değişimi [7]

\begin{tabular}{|c|c|c|}
\hline $\begin{array}{c}\text { TGI } \\
\text { Sınıfları }\end{array}$ & TGI değeri & $\begin{array}{c}\text { Bakım } \\
\text { Gereksinimi }\end{array}$ \\
\hline 1 & TGI $>80$ & Bakıma gerek yok \\
\hline 2 & $50<\mathrm{TGI}<80$ & Basit bakım \\
\hline 3 & $36<\mathrm{TGI}<50$ & Planlı bakım \\
\hline 4 & TGI $<36$ & Acil bakım \\
\hline
\end{tabular}

Amerika'da demiryolu şirketi Amtrak tarafindan yol düzgünsüzlük indeksi, $\mathrm{R}^{2}$ (Running Roughness) geliştirilmiştir. Amtrak, hat geometrisi verilerini sürekli güncellendiği bir veri tabanına sahiptir. Amtrak veri tabanı aynı zamanda yol kayıt aracının topladığı verileri analiz ederek yol düzgünsüzlügünü hesaplamaktadır. $\mathrm{Bu}$ indeks, 
ölçülen standart sapmaların toplamının ölçüm noktası sayısının toplamına bölünmesiyle hesaplanmaktadır ve aşağıdaki şekilde ifade edilmektedir [8].

$\mathrm{R}^{2}=\frac{\sum_{\mathrm{i}=1}^{\mathrm{n}} \mathrm{d}_{\mathrm{i}}^{2}}{\mathrm{n}}$

Burada $n=$ ölçüm sayısı ve $d_{i}$ ölçülen sapma miktarıdır (20 m'lik orta-kiriş dengelemesinden elde edilen). $\mathrm{Bu}$ indeks nivelman, fleş, dever ve hat açıklığı parametreleri için kullanılmaktadır. Çizelge 6 arazi ölçümlerinden elde edilen verilere göre hat koşulları ile düzgünsüzlük indeksi arasındaki ilişkiyi göstermektedir.

Çizelge 6. Düzgünsüzlük indeksinin değerine göre hat koşullarının değişimi [8]

\begin{tabular}{|c|c|}
\hline $\begin{array}{c}\text { Yol } \\
\text { Koşulları }\end{array}$ & $\begin{array}{c}\mathbf{R}^{\mathbf{2}} \text { (Running Roughness) } \\
\text { Değeri }\end{array}$ \\
\hline Çok iyi & $\mathrm{R}^{2}<1$ \\
\hline İyi & $1<\mathrm{R}^{2}<4$ \\
\hline Ortalama & $4<\mathrm{R}^{2}<16$ \\
\hline Kötü & $16<\mathrm{R}^{2}$ \\
\hline
\end{tabular}

Bir başka Amerikan demiryolu organizasyonu olan Federal Demiryolu İdaresi (FRA) de federal yol güvenliği standartlarının (FTSS) bir ekinde yol geometri verilerinden elde edilmiş objektif yol kalite indeksleri (TQI) veri grubunu geliştirmiştir. $\mathrm{Bu}$ indeks yol kalitesini göstermek için uzay eğrisi uzunluğunu kullanmaktadır. Uzay eğrisinin uzunluğu, ardışık veri noktaları arasında ölçülen düz uzunlukların toplanmasıyla hesaplanır ve TQI $161 \mathrm{~m}$ uzunluğundaki yol kesimleri dikkate alınarak hesaplanır. $\mathrm{Bu}$ metoda göre, TQI veri grubu, her fleş, nivelman, dever ve hat açıklığı için aşağıdaki formül kullanılarak hesaplanır [9].

$\mathrm{TQI}=\left[\frac{\mathrm{L}_{\mathrm{s}}}{\mathrm{L}_{0}}-1\right] \times 10^{6}$
Burada, $\mathrm{L}_{\mathrm{S}}$ izlenen uzay eğrisi uzunluğu, $\mathrm{L}_{0}$, yol kesiminin teorik uzunluğudur. TQI değeri farklı özellikteki yol kesimleri (kurplar, köprüler, tüneller, makaslar gibi ) ayrı ayrı değerlendirilmeli ve buna göre gruplanmalıdır.

İranlı araştırmacı Sadeghi tarafından geliştirilen bir başka indekste hat geometrisi verisinin istatistiksel dağılımından faydalanılmıştır. $\mathrm{Bu}$ indeksin hesabı için, ölçüm aracının her $25 \mathrm{~cm}$ de bir okuma yaparak elde ettiği verilerin istatistik olarak normal dağılıma uyduğu kabul edilmiş ve göz önüne alınan geometri parametreleri olan ekartman, nivelman, fleş ve burulmanın her biri için aşağıdaki formüller kullanılarak ayrı ayrı indeks değerleri hesaplanmıştır [4].

$G I^{+}=\left|\bar{X}_{\text {Ekartman }}+3 * S D_{\text {Ekartman }}\right|$

$G I^{-}=\left|\bar{X}_{\text {Ekartman }}-3 * S D_{\text {Ekartman }}\right|$

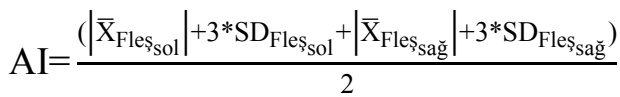

$\mathrm{PI}=\frac{\left(\left|\overline{\mathrm{X}}_{\text {Nivelman }_{\text {sol }}}\right|+3 * \mathrm{SD}_{\text {Nivelman }_{\text {sol }}}+\left|\overline{\mathrm{X}}_{\text {Nivelman }_{\text {să }}}\right|+3 * \mathrm{SD}_{\text {Nivelman }_{\text {să̈ }}}\right)}{2}$

$\mathrm{TI}=\left|\overline{\mathrm{X}}_{\text {Burulma }}\right|+3 * \mathrm{SD}_{\text {Burulma }} \mid$

Verilen formüllerde, $\mathrm{GI}^{+}$, pozitif ekartman indeksi, $\mathrm{GI}^{-}$, negatif ekartman indeksi, AI, fleş indeksi, PI, nivelman indeksi ve TI, burulma indeksidir. Formüllerdeki $\bar{X}$ her bir parametre için aritmetik ortalamayı ve SD ise standart sapmayı temsil etmektedir.

Her geometri parametresi için ayrı ayrı indekslerin oluşturulmasından sonra bu indekslerin kombinasyonundan oluşan ve hattın genel geometrik şartları hakkında bilgi veren tüm hattın geometri indeksi (OTGI) türetilmiştir. Bu işlem yapılırken geometri parametrelerinin indekslerine 
önem derecelerine göre ağırlıklar atanmış ve Eşitlik 10'da elde edilmiştir.

$$
\text { OTGI }=\frac{\frac{a^{2} * \mathrm{GI}^{+}+\frac{\mathrm{a}^{\prime}}{2} * \mathrm{GI}^{-}+\mathrm{b}^{\prime} * \mathrm{AI}+\mathrm{c} * \mathrm{PI}+\mathrm{d}^{\prime} * \mathrm{TI}}{\frac{\mathrm{a}+\mathrm{a}^{\prime}}{2}+\mathrm{b}+\mathrm{c}+\mathrm{d}}}{2}
$$

OTGI göz önüne alınan tüm hat kesimi için geometri indeksidir. Burada a, a', b, c ve d geometri parametrelerinin indekslerinin önem katsayılarıdır. $\mathrm{Bu}$ katsayılar geometri parametrelerinin tolerans değerlerinin birbirlerine oranlanması ile elde edilmiştir. Önem katsayıları, geçen trafik yoğunluğu ve izin verilen tren hızı değerine göre belirlenen, demiryolu hattının sınıfına göre (Çizelge 7) farklı değerler almaktadır. Önem katsayılarının farklı değerler almasıyla OTGI değeri de demiryolu hattının sınıfına göre değişim göstermektedir (Çizelge 8)

Çizelge 7. Demiryolu hat sınıflarının tanımı [4]

\begin{tabular}{|c|c|c|c|c|}
\hline \multirow{2}{*}{$\begin{array}{c}\text { Trafik Yoğunluğu } \\
\text { (MGT/yıl) }\end{array}$} & \multicolumn{4}{|c|}{ Hizlar(km/s) } \\
\hline & $>160$ & $120-160$ & $80-120$ & $<80$ \\
\hline$>15$ & $\mathrm{~A}_{1}$ & $\mathrm{~B}_{1}$ & $\mathrm{C}_{1}$ & $\mathrm{D}_{1}$ \\
\hline $10-15$ & $\mathrm{~A}_{2}$ & $\mathrm{~B}_{2}$ & $\mathrm{C}_{2}$ & $\mathrm{D}_{2}$ \\
\hline $5-10$ & $\mathrm{~A}_{3}$ & $\mathrm{~B}_{3}$ & $\mathrm{C}_{3}$ & $\mathrm{D}_{3}$ \\
\hline$<5$ & $\mathrm{~A}_{4}$ & $\mathrm{~B}_{4}$ & $\mathrm{C}_{4}$ & $\mathrm{D}_{4}$ \\
\hline
\end{tabular}

Çizelge 8. Demiryolu hat sınıfları için izin verilen OTGI değerleri [4]

\begin{tabular}{|c|c|c|c|c|}
\hline Hat Sinıfi & $\mathbf{1}$ & $\mathbf{2}$ & $\mathbf{3}$ & $\mathbf{4}$ \\
\hline A & $0<$ OTGI $<2,19$ & $2,19<$ OTGI $<4,91$ & $4,91<$ OTGI $<9,27$ & $9,27<$ OTGI $<14,63$ \\
\hline B & $0<$ OTGI $<3,02$ & $3,02<$ OTGI $<6,26$ & $6,26<$ OTGI $<11,81$ & $11,81<$ OTGI $<18,03$ \\
\hline C & $0<$ OTGI $<3,62$ & $3,62<$ OTGI $<7,23$ & $7,23<$ OTGI $<13,68$ & $13,68<$ OTGI $<19,35$ \\
\hline D & $0<$ OTGI $<7,06$ & $7,06<$ OTGI $<8,70$ & $8,70<$ OTGI $<15,37$ & $15,37<$ OTGI $<22,55$ \\
\hline
\end{tabular}

Bu çalışmada Ankara-Eskişehir Yükssek Hızlı Tren (YHT) hattından elde edilen hat geometrisi ölçümleri analiz edilerek hattın farklı kesimlerine ait kalite indeksleri hesaplanmıştır. Kalite indekslerinin hesaplandiktan sonra hat kalitesine etki eden parametreleri belirlemek için regresyon modelleri oluşturulmuştur.

\section{MATERYAL VE METOT}

$\mathrm{Bu}$ çalışma için TCDD YHT dairesi tarafindan Ankara-Eskişehir YHT hattında yapılan yol kontrol çalışmalarından elde edilen hat geometrisi verileri kullanılmıştır. Ankara-Eskişehir hattı 2009 yılında işletmeye açılmıştır ve sadece yolcu treni trafiğine hizmet etmektedir. Yük trenlerinin oluşturduğu trafiğin görülmediği bu hatta konvansiyonel hatlara nazaran daha düşük trafik yükleri oluşmaktadır. Bu hatta yapılan yol kontrol çalışmalarında, $250 \mathrm{~km} / \mathrm{s}$ hızla giderken her $0,25 \mathrm{~m}$ de bir hat geometrisi parametrelerini ölçebilme kapasitesine sahip Piri Reis hat kontrol treni kullanılmıştır. Piri Reis yol kontrol treni hat geometrisi ölçümlerini EN-138548-5 standardında belirtilen eşik değerlere göre yapmaktadır. Yapılan hat kontrol çalışmalarında çift hatlı olarak tasarlanmış YHT hattındaki her bir ray dizisi için ekartman, nivelman, fleş ve burulma değerleri ölçülmektedir. EN-138548-5 standardına göre hat geometrisinin kalite göstergesi olarak, her bir ray dizisi için ayrı ayrı belirlenmek üzere, geometri parametrelerinin noktasal ölçümleri ve 200 metre uzunluğundaki hat kesimleri için geometri değerlerinin standart sapması göz önüne alınmaktadır. Geometri parametrelerinin noktasal ölçümü ile hat üzerinde geometrik kusur oluşan yerler belirlenirken, belirli uzunluktaki hat kesimleri için standart sapma değerlerinin hesaplanması ile dikkate alınan kesim için geometrik kalite değeri belirlenmektedir. Ayrıca EN 13848-5'de standart sapma analizi fleş ve nivelman parametreleri için yapılmaktadır. 
Bu çalışmada dikkate alınan hızlı tren hattının geometrik kalitesinin değişimini incelemek üzere hat boyunca farklı zamanlarda yapılan fleş ve nivelman parametrelerine ait ölçümlerden yararlanılmıştır. EN-138548-5'e göre nivelman ve fleş parametreleri için eşik değerlerin hıza bağlı olarak değişimi Çizelge 9 ve Çizelge 10 'da görülmektedir. $\mathrm{Bu}$ çizelgelerde geometri parametrelerinin noktasal ölçümleri için 3 düzey gösterilmiştir. Bunlar: Aşılması halinde yol geometrisi koşullarının düzenli ve planlı bakım çalışmaları kapsamında analiz edilmesini ve dikkate alınmasını ifade eden "Uyarı eşik değerleri
(AL)", aşılması halinde bir sonraki ölçüme kadar emniyet eşiğine varmadan bakım ve tamirat çalışmalarını gerektiren değerleri ifade eden "Müdahale eşik değerleri (IL)" ve aşılması halinde bozulmalar düzeltilinceye kadar maksimum tren hızını düşürmek veya hattı işletmeye kapatmak şeklinde acil önlem alınması gerektiğini ifade eden "Emniyet eşik değerleri (IAL)" olarak sıralanmaktadır. Ayrıca bu eşik değerler geometri kusurlarının dalga boyları $(\lambda)$ olan D1 $(3 \mathrm{~m}<\lambda \leq 25 \mathrm{~m})$ ve D2 $(25 \mathrm{~m}<\lambda \leq 70 \mathrm{~m})$ değerlerine göre değişmektedir.

Çizelge 9. Nivelman parametresi için eşik değerler [10]

\begin{tabular}{|c|c|c|c|c|c|c|c|}
\hline \multirow{2}{*}{$\begin{array}{c}\text { Hizlar } \\
\mathbf{K m} / \mathbf{s})\end{array}$} & \multicolumn{2}{|c|}{ AL(mm) } & \multicolumn{2}{c|}{ IL (mm) } & IAL (mm) & Standart Sapma \\
\cline { 2 - 7 } & $\mathbf{D 1}$ & $\mathbf{D 2}$ & D1 & D2 & D1 & D2 & D1 \\
\hline $\mathrm{V} \leq 80$ & $12-18$ & $\mathrm{~N} / \mathrm{A}$ & $17-21$ & $\mathrm{~N} / \mathrm{A}$ & 28 & $\mathrm{~N} / \mathrm{A}$ & $2,3-3$ \\
\hline $80<\mathrm{V} \leq 120$ & $10-16$ & $\mathrm{~N} / \mathrm{A}$ & $13-19$ & $\mathrm{~N} / \mathrm{A}$ & 26 & $\mathrm{~N} / \mathrm{A}$ & $1,8-2,7$ \\
\hline $120<\mathrm{V} \leq 160$ & $8-15$ & $\mathrm{~N} / \mathrm{A}$ & $10-17$ & $\mathrm{~N} / \mathrm{A}$ & 23 & $\mathrm{~N} / \mathrm{A}$ & $1,4-2,4$ \\
\hline $160<\mathrm{V} \leq 220$ & $7-12$ & $14-20$ & $9-14$ & $18-23$ & 20 & 33 & $1,2-1,9$ \\
\hline $220<\mathrm{V} \leq 300$ & $6-10$ & $12-18$ & $8-12$ & $16-20$ & 17 & 28 & $1,0-1,5$ \\
\hline
\end{tabular}

Çizelge 10. Fleş parametresi için eşik değerler [10]

\begin{tabular}{|c|c|c|c|c|c|c|c|}
\hline \multirow{2}{*}{$\begin{array}{c}\text { Hizlar } \\
(\mathbf{K m} / \mathbf{s})\end{array}$} & \multicolumn{2}{|c|}{$\mathbf{A L}(\mathbf{m m})$} & \multicolumn{2}{|c|}{ IL (mm) } & \multicolumn{2}{c|}{ IAL (mm) } & Standart Sapma \\
\cline { 2 - 7 } & D1 & D2 & D1 & D2 & D1 & D2 & D1 \\
\hline $\mathrm{V} \leq 80$ & $12-15$ & N / A & $15-17$ & N / A & 22 & N / A & $1,5-1,8$ \\
\hline $80<\mathrm{V} \leq 120$ & $8-11$ & N / A & $11-13$ & N / A & 17 & N / A & $1,2-1,5$ \\
\hline $120<\mathrm{V} \leq 160$ & $6-9$ & N / A & $8-10$ & N / A & 14 & N / A & $1,0-1,3$ \\
\hline $160<\mathrm{V} \leq 220$ & $5-8$ & $10-15$ & $7-9$ & $14-17$ & 12 & 24 & $0,8-1,1$ \\
\hline $220<\mathrm{V} \leq 300$ & $4-7$ & $8-13$ & $6-8$ & $12-14$ & 10 & 20 & $0,7-1,0$ \\
\hline
\end{tabular}

Çizelge 9 ve Çizelge 10'un son sütularında ise standart sapma değerlerine yer verilmiştir. Standart sapma değerleri her bir ray dizisi için ayrı ayrı belirlenir ve böylece incelenen herhangi bir demiryolu kesimi için 2 adet standart sapma değeri elde edilmiş olunur. $\mathrm{Bu}$ değerlerden büyük olanı dikkate alınan kesim için kalite göstergesi olan standart sapma değeri olarak kabul edilir.

Demiryolu bakım ve onarım çalışmaları belirli bir plan çerçevesinde yapıldı ̆̆ı zaman eldeki maddi olanakların etkin bir şekilde kullanımı sağlanmış olur. $\mathrm{Bu}$ planlar yürütülürken demiryolu hattı genellikle 200 metre uzunluğunda kontrol kesimlerine ayrılır. Bu çalıșmada TCDD YHT dairesinden elde edilen veriler doğrultusunda hat analiz kesimlerine ayrılmıștır. Analiz kesimleri hattın güzergah geometrisi dikkate alınarak oluşturulmuștur. Dikkate alınan YHT hattının $518+880$ ile $322+211$ kilometreleri arasında kalan yaklaşık 197 km'lik kesimi, güzergah geometrisine göre 46 alinyman ve 70 yatay kurptan oluşmaktadır. Bu yatay kurp ve alinyman kesimleri ana kesimleri oluşturmaktadır. $\mathrm{Bu}$ ana kesimler ise kendi içinde uzunlukları 200 metre olan alt kesimlere bölünmüştür. Fakat ana kesim uzunluklarının aldığı farklı değerlerden dolayı 200 metrelik kesimlerden farklı olarak en küçüğü $100 \mathrm{~m}$ en büyüğü $400 \mathrm{~m}$ olan farklı uzunluklarda alt kesimler de oluşturulmuştur. Kurplu kesimler alt kesimlere ayrılırken kurpların birleştirme eğrileri bulunduğu kesimler kendi içinde alt 
kesimlere ayrılmış ve bu kesimlere parabol alt kesimi adı verilmiştir. Geometri ve uzunluk kriterleri göz önüne alındığı zaman hat ana kesimlerin altında 350 alinyman, 507 yatay kurp, 112 parabol ve toplam uzunlukları 400 metreden kısa olduğu için bir arada değerlendirilmiş 20 adet parabol+yatay kurp+parabol'dan oluşan 989 alt kesime ayrılmıştır. Daha sonra her bir alt kesim için EN-138548-5 standardında belirtilen eşik değerlere göre hat kalitesinin göstergesi olarak fleş ve nivelman parametreleri için standart sapma değerleri hesap edilmiştir.

Çalışmaya konu olan YHT hattının kesimlerine ait kalite göstergeleri olan standart sapma değerleri hesaplandiktan sonra hat kalitesine etki eden parametreleri belirlemek için birden fazla bağımsız değişken ve bir adet bağımlı değişken kullanılarak uygulanan çok değişkenli regresyon analizi tekniğinden yararlanılmıştır.

Çok değişkenli regresyon tekniğinin uygulandığı problemler birden fazla bağımsız değişkenin etkisiyle ortaya çıkmaktadır. Bu tür problemlerde birden fazla sayıda bağımsız değişken bir araya gelerek probleme konu olan bağımlı değişkeni etkileyebilmektedirler. $\mathrm{Bu}$ bağımsız değişkenler aynı zamanda kendi aralarında da birbirlerini etkileyebilmektedir. $\mathrm{Bu}$ teknik ile bağımsız değişkenleri ve bağımlı değişkeni arasındaki matematiksel ilişki belirlenebilmektedir [11]

\section{BULGULAR}

İncelenen YHT hattı çift hattan oluşmaktadır. Yapılan ilk incelemede komşu hatlarda meydana bozulmaların birbirlerine benzer büyüklüklerde ve yaklaşık olarak aynı kesimlerde meydana geldiği gözlenmiştir. Bundan dolayı sadece bir hatta meydana gelen bozulmalar incelenmiştir. Dikkate alınan $197 \mathrm{~km}$ uzunlukta olan ve 989 alt kesime ayrılmış hatta, 2011 ve 2012 yıllarında yapılan 6 farklı ölçümün sonuçlarına göre yalnızca 43 farklı kesimde noktasal kusurların oluştuğu görülmüştür. Bundan dolayı araştırmada kusur meydana gelen kesimler üzerinde odaklanılmıştır.

Noktasal kusur incelemesinden sonra hat kalitesine etki eden parametrelerin belirlenmesi amacıyla çok değişkenli regresyon modelleri kurulmuştur. Modeller hat kalitesinin göstergesi olan fleş ve nivelman parametrelerinin standart sapma değerlerinin değişimine etki eden etkenleri belirlemek amaciyla her bir parametre için ayrı ayrı üretilmiştir. Buna göre bağımlı değişkenler;

- $\quad$ Sağ ve sol ray dizilerine ait fleş değerlerinin standart sapma değerlerinden büyük olanı; maks_Fleş_std

- Sağ ve sol ray dizilerine ait nivelman değerlerinin standart sapma değerlerinden büyük olanı; maks_Nivelman_std

olarak belirlenmiştir. Bağımlı değişkenleri açıklamak için kullanılan bağımsız değişkenler ise;

- Yatay kurba yarıçapı (R) (m)

- Boyuna eğim (s) (\%o)

- Dever (d) (mm)

- Toplam geçen trafik $\left(\mathrm{T}_{1}\right)$ (tren seti sayısi)

- Makineli tamirattan sonra geçen trafik $\left(\mathrm{T}_{2}\right)$ (tren seti sayıs1)

- Ölçümler arası geçen trafik $\left(\mathrm{T}_{3}\right)$ (tren seti sayısı)

- Ortalama aylık sicaklık (t) $\left(\mathrm{C}^{\mathrm{o}}\right)$

- Ortalama aylık yağış (y) (mm)

- Alt kesim tipi (KT) (aliyman, kurp)

- Bağımlı değişkenin bir önceki ölçümdeki değeri (e_maks_Fleş_std, e_maks_Nivelman_std,)

olarak sıralanmıştır.

Regresyon analizinde bağımsız değişkenler sayısal veriler tipinde olduğu gibi nitelik bildiren sözel verilerde olabilir. Bu durumda nitelik bildiren değişkenler kukla değişken olarak hesaba katılırlar. Çalışmada kullanılan alt kesim tipi bağımsız değişkeninde ki aliyman değeri “ 0 ”, kurp değeri ise "1" kabul edilerek hesaplara dahil edilmiştir. Ortalama aylık sıcaklık ve ortalama aylık yağış verileri ise Orman $\mathrm{Ve} \mathrm{Su}$ İşleri Bakanlığı Meteoroloji Genel Müdürlüğü'nden temin edilmiştir [12].

Trafiği ait veriler ise dikkate alınan hattan ölçümlerin yapıldı ̆̆ dönemde geçen tren seti sayısı olarak ifade edilmiştir. Çünkü dikkate alınan ölçüm dönemlerinde bu hatta çalışan tren setleri büyüklük olarak aynı özelliklere sahiptir. Ayrıca 
ölçümlerin yapıldığı dönemlerde her bir hatta, var olan tren setleri ile günde ortalama 10 sefer yapıldığı tespit edilmiştir. Bu durum YHT hattının düşük trafik hacmine sahip olduğunu göstermektedir.

$\mathrm{Bu}$ çalışmada oluşturulan çoklu regresyon modelleri SPSS programı vasitasiyla oluşturulmuştur. İlk oluşturulan modellerde bütün bağımsız değişkenler hesaba dahil eden "enter" metodu kullanılmıştır. Çizelge 11'de "maks_Fleş _std" bağımlı değişkeni için oluşturulan "enter" metodu kullanılarak oluşturulan regresyon modeline ilişkin bilgiler verilmiştir. Buna göre modelin $R$ değeri 0,852 ve $R^{2}$ değeri ise 0,727 olarak hesaplanmıştır. \%95 güven aralığında $\mathrm{p}<0,05$ anlamlılık düzeyinde, bağımlı değişkenle bağımsız değişkenler arasında anlamlı bir model oluşturulduğu görülmüştür.

Çizelge 11'de ki modelin katsayılar tablosuna bakıldığı zaman ise "maks_Fleş_std" parametresi üzerinde etkili olan değişkenlerin, $\quad p<0,05$ anlamlılık değerine sahip olan "Ölçümler Arası Geçen Trafik" ve "Bağımlı Değişkenin Önceki Değeri" değişkenleri olduğu görülmektedir. p $>0,05$ olan diğer değişkenler ile bağımlı değişken arasında ise istatistiksel olarak anlamlı bir ilişki olmadığı görülmektedir. Bundan dolayı bağımlı değişkeni açıklamaya katkısı olmayan bağımsız değişkenlerin hesaptan çıkarılması gerekmektedir.

Çizelge 11. "maks_Fleş__std” için enter metodu kullanılarak oluşturulan çoklu regresyon analizi sonuçları

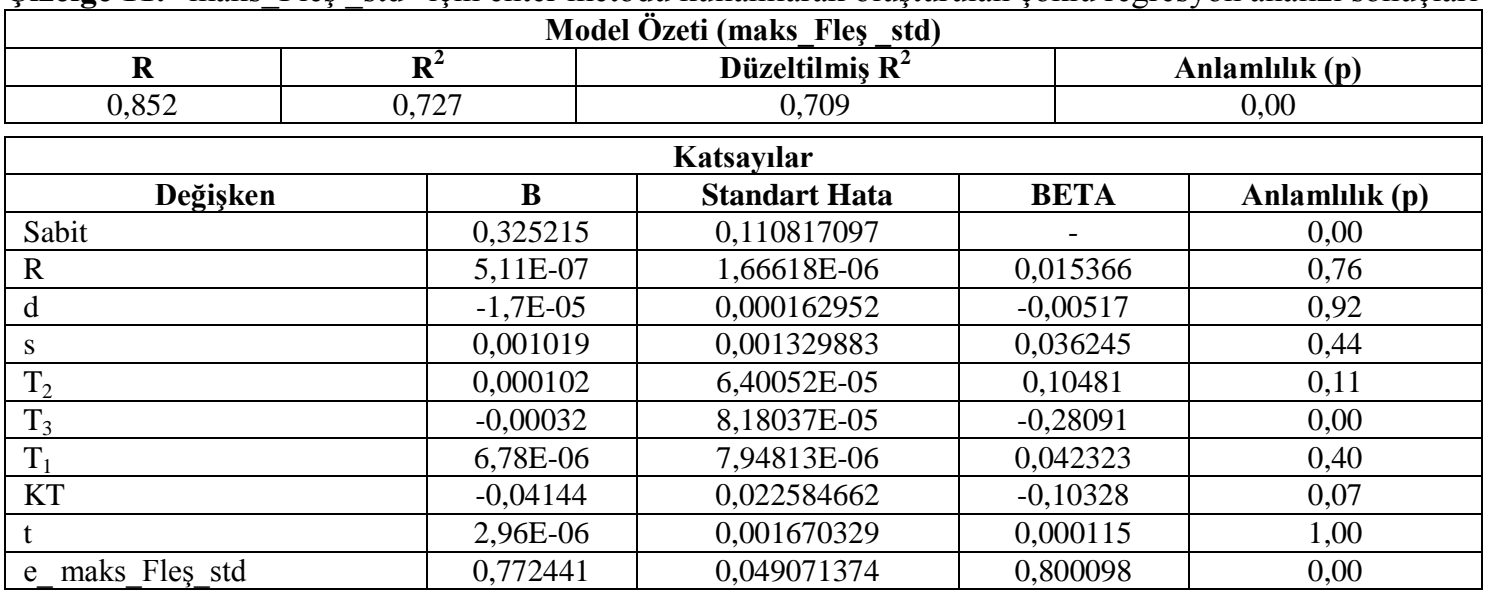

Regresyon modeline katkısı olmayan değişkenleri modelden çıkarmak için birden fazla yöntem vardır. Bu çalışmada "stepwise" yöntemi kullanılarak bağımlı değişkene etkisi olmayan değişkenler modelden çıkarılmıştır. Bu yöntemde sırayla her değişken modele eklenir ve değerlendirilir. Modele dahil edilen değişken bağımlı değişkeni açıklamaya katkı sağlıyorsa eklenen değişken model de kalır. Bundan sonra modeldeki diğer değişkenlerin tamamının modele olan katkısı yeniden değerlendirilir. Eğer önemli bir katkıları yoksa modelden çıkarılır.

Çizelge 12'de fleş parametresine bağlı kalite göstergesi olarak kullanılan, fleş parametresinin standart sapması değerini temsil eden "maks_Fleş std" bağımlı değişkeni için "stepwise" yöntemi kullanılarak oluşturulan regresyon denklemi ile ilgili sonuçlar verilmiştir. Buna göre bağımlı değişkeni açıklamak için bağımsız değişkenlerin modele eklenip çıkarılması ile 3 model oluşturulmuştur. Bütün modeller de \%95 güven aralığında $\mathrm{p}<0,05$ anlamlılık düzeyinde bağımlı değişkenle bağımsız değişkenler arasında anlamlı bir ilişki bulunmuştur. Model özeti tablosundaki Durbin-Watson değeri (1,5-2,5 arasında olmalı) modellerdeki bağımsız değişkenler arasında otokorelasyon olmadığını göstermektedir. "maks Fleş std" bağımlı değişkeni için oluşturulan modeller içinde $\mathrm{R}$ değeri 0,847 ve $\mathrm{R}^{2}$ 
değeri 0,717 olan üçüncü modelin bağımlı değişkeni en yüksek açıklama oranına sahip olduğu görülmektedir. Katsayılar tablosuna bakıldığ zaman oluşturulan üç modelde de $\mathrm{p}<0,05$ için bütün değişkenlerin anlamlı olduğu görülmektedir. BETA katsayılarına göre modeldeki en önemli bağımsız değişkenin, en büyük değere sahip olan "bağımlı değişkenin önceki değeri” (e_maks_Fleş_std) olduğu görülmektedir. Ayrıca $\mathrm{B}^{-}$katsayılarına göre "ölçümler arası geçen trafik" $\left(\mathrm{T}_{3}\right)$ değişkenin 0 değeri ile modele katkısının olmadığ düşünülmektedir. Çizelge 12'ye göre "kesim tipi" (KT) değişkenin fleş parametresinin standart sapması üzerinde negatif etkisi vardır. Bunlardan başka "ortalama aylık sıcaklık" ve "ortalama aylık yağış" parametreleri ile temsil edilen iklim koşullarının "maks_Fleş_std" bağımlı değişkeni üzerinde bir etkisinin olmadığ 1 görülmüştür.

Çizelge 12. "maks_Fleş_std" için stepwise yöntemi kullanılarak oluşturulan çoklu regresyon analizi sonuçları

\begin{tabular}{|c|c|c|c|c|c|}
\hline \multicolumn{7}{|c|}{ Model Özeti (maks_Fleș_std) } \\
\hline Model & $\mathbf{R}$ & $\mathbf{R}^{\mathbf{2}}$ & Düzeltilmiş R & $\begin{array}{c}\text { Durbin- } \\
\text { Wahminlerin } \\
\text { Standart Hatasın }\end{array}$ \\
\hline 1 & 0,812 & 0,659 & 0,657 & 0,116377 & \multirow{2}{*}{1,743} \\
\hline 2 & 0,842 & 0,709 & 0,705 & 0,1079439 & \\
\hline 3 & 0,847 & 0,717 & 0,711 & 0,1068359 & \\
\hline
\end{tabular}

\begin{tabular}{|c|c|c|c|c|c|c|}
\hline \multicolumn{7}{|c|}{ Katsayılar } \\
\hline \multirow{2}{*}{$\begin{array}{l}\text { Model } \\
\text { No }\end{array}$} & \multirow[t]{2}{*}{ Bağımsız Değişkenler } & \multicolumn{2}{|c|}{$\begin{array}{c}\text { Standartlaştırılmamış } \\
\text { Katsayılar }\end{array}$} & \multirow{2}{*}{$\begin{array}{c}\begin{array}{c}\text { Standartlaştırılmış } \\
\text { Katsayılar }\end{array} \\
\text { Beta } \\
\end{array}$} & \multirow[t]{2}{*}{$\mathbf{t}$} & \multirow[t]{2}{*}{ Anlamlılık } \\
\hline & & $\mathbf{B}$ & Standart Hata & & & \\
\hline \multirow{2}{*}{1} & (Sabit) & 0,113 & 0,027 & & 4,199 & 0 \\
\hline & e_maks_Fleş_std & 0,784 & 0,046 & 0,812 & 17,043 & 0 \\
\hline \multirow{3}{*}{2} & (Sabit) & 0,383 & 0,059 & & 6,472 & 0 \\
\hline & e_maks_Fleş_std & 0,824 & 0,043 & 0,854 & 18,988 & 0 \\
\hline & $\mathrm{T}_{3}$ & 0 & 0 & $-0,226$ & $-5,035$ & 0 \\
\hline \multirow{4}{*}{3} & (Sabit) & 0,423 & 0,062 & & 6,844 & 0 \\
\hline & e_maks_Fleş_std & 0,782 & 0,048 & 0,81 & 16,408 & 0 \\
\hline & $\mathrm{T}_{3}$ & 0 & 0 & $-0,222$ & $-4,983$ & 0 \\
\hline & KT & $-0,039$ & 0,019 & $-0,098$ & $-2,026$ & 0,045 \\
\hline
\end{tabular}

Çizelge 13'de nivelman parametresine bağlı kalite göstergesi olan, nivelman parametresinin standart sapmasını temsil eden "maks_Nivelman_std" bağımlı değişkeni için oluşturulan altı regresyon modeline ilişkin bilgiler verilmiştir. Buna göre bağımlı değişkeni açıklamak için bağımsız değişkenlerin modele eklenip çıkarılması ile 6 model oluşturulmuştur. Bütün modeller de \%95 güven aralığında $\mathrm{p}<0,05$ anlamlılık düzeyinde bağımlı değişkenle bağımsız değişkenler arasında anlamlı bir ilişki bulunmuştur. Model özeti tablosundaki Durbin-Watson değeri modellerdeki bağımsız değişkenler arasında otokorelasyon olmadığını göstermektedir. "maks_Nivelman_std" bağımlı değişkeni için oluşturulan modeller içinde en yüksek $R$ değeri 0,784 ve $R^{2}$ değeri 0,615 olan altıncı modelin bağımlı değişkeni en yüksek açıklama oranına sahip olduğu görülmektedir. 
Çizelge 13. “maks_Nivelman_std” için stepwise yöntemi kullanılarak oluşturulan çoklu regresyon analizi sonuçları

\begin{tabular}{|c|c|c|c|c|c|}
\hline \multicolumn{6}{|c|}{ Model Özeti (maks_Nivelman_std) } \\
\hline Model No & $\mathbf{R}$ & $\mathbf{R}^{2}$ & Düzeltilmiş $\mathbf{R}^{2}$ & $\begin{array}{c}\text { Tahminlerin } \\
\text { Standart Hatası }\end{array}$ & $\begin{array}{l}\text { Durbin- } \\
\text { Watson }\end{array}$ \\
\hline 1 & $0,704(\mathrm{a})$ & 0,495 & 0,491 & 0,2499511 & \multirow{6}{*}{1,85} \\
\hline 2 & $0,741(b)$ & 0,549 & 0,541 & 0,2372956 & \\
\hline 3 & $0,756(\mathrm{c})$ & 0,571 & 0,561 & 0,2322045 & \\
\hline 4 & $0,772(d)$ & 0,597 & 0,584 & 0,2261239 & \\
\hline 5 & $0,768(\mathrm{e})$ & 0,59 & 0,581 & 0,2269642 & \\
\hline 6 & $0,784(\mathrm{f})$ & 0,615 & 0,603 & 0,2208904 & \\
\hline
\end{tabular}

\begin{tabular}{|c|c|c|c|c|c|c|}
\hline \multicolumn{7}{|c|}{ Katsayılar (maks_Nivelman_std) } \\
\hline \multirow{2}{*}{ ModelNo } & \multirow{2}{*}{ Bağımsız Değişkenler } & \multicolumn{2}{|c|}{$\begin{array}{c}\text { Standartlaştırılmamış } \\
\text { Katsayılar }\end{array}$} & \multirow{2}{*}{$\begin{array}{c}\begin{array}{c}\text { Standartlaştırılmış } \\
\text { Katsayılar }\end{array} \\
\text { Beta }\end{array}$} & \multirow[b]{2}{*}{$\mathbf{t}$} & \multirow{2}{*}{ Anlamlılık } \\
\hline & & $\mathbf{B}$ & $\begin{array}{l}\text { Standart } \\
\text { Hata }\end{array}$ & & & \\
\hline \multirow{2}{*}{1} & (Sabit) & 0,262 & 0,058 & & 4,487 & 0 \\
\hline & e_maks_Nivelman_std & 0,768 & 0,069 & 0,704 & 11,119 & 0 \\
\hline \multirow{3}{*}{2} & (Sabit) & 0,334 & 0,059 & & 5,703 & 0 \\
\hline & e_maks_Nivelman_std & 0,797 & 0,066 & 0,731 & 12,08 & 0 \\
\hline & $\mathrm{t}$ & $-0,012$ & 0,003 & $-0,233$ & $-3,847$ & 0 \\
\hline \multirow{4}{*}{3} & (Sabit) & 0,683 & 0,148 & & 4,614 & 0 \\
\hline & e_maks_Nivelman_std & 0,791 & 0,065 & 0,725 & 12,233 & 0 \\
\hline & $\mathrm{t}$ & $-0,009$ & 0,003 & $-0,171$ & $-2,678$ & 0,008 \\
\hline & $\mathrm{T}_{3}$ & 0 & 0 & $-0,162$ & $-2,558$ & 0,012 \\
\hline \multirow{5}{*}{4} & (Sabit) & 0,619 & 0,146 & & 4,24 & 0 \\
\hline & e_maks_Nivelman_std & 0,809 & 0,063 & 0,741 & 12,781 & 0 \\
\hline & $\mathrm{t}$ & $-0,005$ & 0,003 & $-0,094$ & $-1,387$ & 0,168 \\
\hline & $\mathrm{T}_{3}$ & $-0,001$ & 0 & $-0,395$ & $-3,801$ & 0 \\
\hline & $\mathrm{T}_{2}$ & 0,001 & 0 & 0,27 & 2,785 & 0,006 \\
\hline \multirow{4}{*}{5} & (Sabit) & 0,649 & 0,145 & & 4,477 & 0 \\
\hline & e_maks_Nivelman_std & 0,803 & 0,063 & 0,736 & 12,668 & 0 \\
\hline & $\mathrm{T}_{3}$ & $-0,001$ & 0 & $-0,472$ & $-5,331$ & 0 \\
\hline & $\mathrm{T}_{2}$ & 0,001 & 0 & 0,324 & 3,647 & 0 \\
\hline \multirow{5}{*}{6} & (Sabit) & 0,593 & 0,142 & & 4,168 & 0 \\
\hline & e_maks_Nivelman_std & 0,827 & 0,062 & 0,758 & 13,278 & 0 \\
\hline & $\mathrm{T}_{3}$ & $-0,001$ & 0 & $-0,53$ & $-5,981$ & 0 \\
\hline & $\mathrm{T}_{2}$ & 0,001 & 0 & 0,396 & 4,391 & 0 \\
\hline & $\mathrm{R}$ & $-1,00 \mathrm{E}-05$ & 0 & $-0,165$ & $-2,813$ & 0,006 \\
\hline
\end{tabular}

Çizelge 13'de ki altıncı modelin katsayılar tablosuna bakıldığında BETA değerlerine göre "maks_Nivelman_std" parametresi üzerinde etkili olan bağımsız değişkenlerin önem derecesine göre, "bağımlı değişkenin önceki değeri (e_maks_Nivelman_std)", “ölçümler arası geçen trafik $\left(\mathrm{T}_{3}\right)$ ", "tamirattan sonra geçen trafik $\left(\mathrm{T}_{2}\right)$ " ve "yatay kurp yarıçapı (R)" olarak sıralanmaktadır. Ayrıca B katsayıları incelendiği zaman “maks_Nivelman_std" parametresi üzerinde etkili olan en anlamlı değişkenin bu parametrenin bir önceki ölçümdeki değerini temsil eden "e_maks_Nivelman_std" değişkeni olduğu görülmektedir. Her ne kadar trafiği ait değişkenlerin $\left(T_{3}, T_{2}\right)$ ve kurp yarıçapının (R) modellerde istatistiksel olarak anlamlı olduğu görülse de aldıkları düşük B katsayısı değerleri ile modele çok önemli katkılarının olmadığı görülmektedir. Bunlardan başka "ortalama aylık sıcaklık" ve "ortalama aylık yağış" parametreleri 
ile temsil edilen iklim koşullarının "maks_Nivelman_std" bağımlı değişkeni üzerinde bir etkisinin olmadığı görülmüştür.

\section{SONUÇLAR}

$\mathrm{Bu}$ çalışmada Ankara-Eskişehir YHT hattına ait geometri verilerinden yararlanılarak düşük trafik hacmine sahip yüksek hızlı tren hattında hat kalitesine etki eden etkenler araştırılmıştır. Çalışmada ilk olarak dikkate alınan YHT hattı güzergah geometrisi dikkate alınarak alt kesimlere ayrılmış ve EN134848-5'te belirtilen eşik değerlere göre bu alt kesimlerde meydan gelen bozulmalar tespit edilmiştir. Yapılan incelemede 2011 ve 2012 yıllarında yapılan 6 ölçüm sonucunda 989 alt kesimin yalızca 43'ünde geometrik bozulma tespit edilmiştir. Bozulma olan kesimler tespit edildikten sonra bu kesimlerin her birinde fleş ve nivelman parametrelerine ait standart sapma değerleri hesaplanmıştır. Daha sonra, hat kalitesine etki eden parametreleri belirlemek üzere fleş ve nivelman ölçümlerinin standart sapmalarını bağımlı değişken olarak dikkate alan çok değişkenli regresyon modelleri oluşturulmuştur. Her bir kalite göstergesi için ayrı ayrı oluşturulan ilk regresyon modellerinde "enter" metodu kullanılmıștır. Bu yöntemle elde edilen modellerde bağımlı değişkenlerle birçok bağımsız değişken arasında anlamlı bir ilişki olmadığı gözlenmiştir. Bundan dolayı modele katkısı olmayan değişkenlerin modelden çıkartılması için "stepwise" yöntemi kullanılmış ve elde edilen sonuçlar yorumlanmıştır.

Elde edilen sonuçlara göre, çalışmaya konu olan YHT hattı gibi düşük trafik yoğunluklu bir demiryolu hattında kısa dönemler içinde hat kalitesine etki eden en önemli parametrenin hat kalitesinin bir önceki ölçümdeki değeri olduğu belirlenmiştir. Trafiğe ait bağımsız değişkenlerin ve incelenen hat kesiminin tipinin ise hat kalitesi üzerindeki etkilerinin çok küçük olduğu gözlenmiştir. Ayrıca hattın bulunduğu bölgedeki sıcaklık ve yağış durumunun göz önüne alınan süreler içinde hat kalitesine bir etkisinin olmadığ gözlenmiştir.

\section{KAYNAKLAR}

1. Bing, A.J., Gross, A., 1983. Development of Railway Track Degradation Models, Transportation Research Record, 939, p. 27-3.

2. Berawi, A.R.B., Delgado, R., Calçada, R., Vale, C., 2010. Evaluating Track Geometrical Quality Through Different Methodologies, International Journal of Technology, 1:38-47.

3. Office for Research and Experiments of the International Union of Railways (ORE), 1981. Quantitative Evaluation of Geometry Track Parameters Determining Vehicle Behavior: Introductory Study to the Problem of Assessing Track Geometry on the Basis of Vehicle Response, ORE C152 Report No. 1, 54p.

4. Sadeghi, J., 2010. Development of Railway Track Geometry Indexes Based on Statistical Distribution of Geometry Data. Journal of Transportation Engineering, ASCE, 136(8), 693-700.

5. Madejski, J., Grabozyk, J., 2000. Continuous Geometry Measurement for Diagnosticsof Tracks and Switches. Silesian Univ. of Technology, Gliwice, Poland, 8-30.

6. Anderson, M., 2002. Strategic Planning of Track Maintenance. State of Art. KTH Royal Institute of Technology, Department of Infrastructure TRITA-INFRA 02-035, p59.

7. Mundrey, J.S., 2008. Railway Track Engineering McGraw-Hill, 659, New Delhi.

8. Ebersöhn, W., Conrad, J.R., 2003. Implementing a Railway Infrastructure Maintenance System, Amtrak, Washington, D.C.

9. Zhang, Y.J., El-Sibaie, M., Lee, S., 2004. FRA Track Quality İndices and Distribution Characteristics. AREMA 2004 Annual Conference, September 19-22, Nashville, (CDROM).

10.EN-13848-5, 2008. Railway ApplicationsTrack-Track Geometry Quality, Part 5: Geometric Quality Levels-Plain line, Brussels.

11. Beyazıt, M., Yeğen Oğuz, E.B., 2005. Mühendisler İçin İstatistik. Birsen Yayınevi, İstanbul, s.197. 
12. Orman ve Su İşleri Bakanlığı Meteoroloji Genel Müdürlüğü (MGM), İl ve İlçelerimize ait İstatistikî Veriler. http://www.mgm.gov.tr/ veridegerlendirme/il-ve-ilceler-istatistik.aspx\# sfU, 03.05.2014 
